\title{
A INFLUÊNCIA DA SOCIALIZAÇÃO PRIMÁRIA NA CONSTRUÇÃO DA IDENTIDADE DE GÊNERO: PERCEPÇÕES DOS PAIS
}

\author{
Fernanda Ortiz Costa \\ Adriane Scomazzon Antoniazzill
}

\begin{abstract}
RESUMO: A teoria da aprendizagem social sugere que a aquisição da identidade de gênero é o resultado de um processo evolutivo. Os pais são apontados como os maiores responsáveis pela aquisição da identidade e dos estereótipos de papel de gênero de seus filhos. O objetivo deste estudo foi verificar a influência da socialização primária na construção da identidade de gênero das crianças, através das percepções dos pais. Foram entrevistados 11 pais, 9 mulheres e 2 homens, com idade entre 23 e 40 anos. Os resultados demonstram que a influência dos pais é sutil e que suas crenças sobre papel de gênero determinam diferentes expectativas com relação aos seus filhos e filhas, bem como influenciam o comportamento expresso pelas crianças.
\end{abstract}

Palavras-chave: identidade de gênero, tipificação, papel de gênero

\section{PARENTAL SOCIALIZATION AND GENDER IDENTITY: parents' perception}

\begin{abstract}
Social learning theory suggests that gender identity and sex role stereotypes are outcomes of the developmental process. The influence of the parental socialization about the acquisition of gender identity is considered extremely important. The purposes of the present study were to investigate how parents perceive their influence on this developmental process. Nine mothers and two fathers were interviewed. The results indicate that parental beliefs about sex roles determine different behavioral expectations for sons and daughters and give different patterns of responses to them.
\end{abstract}

Key words: gender identity, sex type, sex role stereotype

A identidade de gênero é o elemento chave no desenvolvimento da personalidade. Influencia o modo de ser, agir e pensar dos indivíduos e constituise no conjunto de crenças, atitudes e estereótipos do indivíduo acerca de gênero, que têm origem em antecedentes biológicos, psicológicos e sociais (Papalia \& Olds, 1998). O processo de construção da identidade de gênero tem importância fundamental para o desenvolvimento dos indivíduos, pois determina interesses, atitudes e comportamentos que o acompanharão ao longo da vida. $\mathrm{O}$ ponto de maior interesse sobre este tema refere-se à maneira pela qual ocorre a formação do conceito de identidade de gênero, através da qual os indivíduos irão perceber a

"Endereço para correspondência : Adriane Scomazzon Antoniazzi, Curso de Pós-Graduação em Psicologia do Desenvolvimento - UFRGS, Rua Ramiro Barcelos, 2600/113, CEP 90035-003, E-mail craa@acay.com.au

Paidéia, FFCLRP-USP, Rib. Preto, junho/99. existência da diferença sexual, posteriormente identificando-se como homens ou mulheres.

Freud (1931) abordou esta questão caracterizando a identificação de gênero como resultado da resolução dos conflitos edípicos, em que as crianças se identificariam com o genitor de mesmo sexo, e elegeriam como objeto amoroso o genitor de sexo oposto. Este processo de identificação iniciarse-ia com a descoberta da diferença anatômica entre os sexos, que ocorreria a partir dos 3 anos de idade.

Segundo teóricos da aprendizagem social, a identificação de gênero é consequiência da observação e imitação de um modelo, que pode ser os pais ou outras pessoas (Bandura \& Hudson, 1961). Quando imitam, as crianças são reforçadas por apresentarem comportamentos adequados ao seu sexo, e são punidas ou não reforçadas quando apresentam comportamentos considerados, socialmente, como inadequados ao mesmo. A partir desta identificação 
os indivíduos tornam-se aptos a desempenharem diferentes papéis sociais vinculados a gênero, e apoiados em suas crenças sobre a diferença entre ser homem e ser mulher. Estes papéis sofrem a influência das expectativas do grupo social e da própria pessoa acerca da maneira "correta" de desempenhá-los. Eles podem ser mais ou menos estereotipados dependendo da situação cultural, social ou da fase de desenvolvimento na qual encontra-se o indivíduo (Bem, 1984).

Crianças podem manifestar seu conhecimento sobre identidade e papel de gênero através da categorização de brinquedos e da escolha de atividades feitas segundo o critério de gênero (Thompson, 1975; Fagot \& Leinbach, 1989). Embora muitos fatores contribuam para este fenômeno, a construção da identidade de gênero e a aquisição de estereótipos de papel de gênero parecem ser o resultado de um processo evolutivo, atribuído a uma função da socialização primária da criança (Snow, Jacklin \& Maccoby, 1983). A aquisição inicial de comportamentos tipificados, percebida através do desempenho de papéis estereotipados de gênero, aparece, assim, como consequiência do reforçamento parental e vinculada à formação de esquemas de gênero, que seriam a base da futura identidade de gênero do indivíduo adulto (Martin \& Havelson, 1983; Fagot \& Leinbach, 1989).

Os pais são apontados como os maiores responsáveis pelo desenvolvimento de estereótipos de papel de gênero nas crianças. Sua influência neste processo supera a possível intervenção de fatores como pares ou a escola (Pellett \& Ignico, 1993). Para Fagot (1978), muitos dos efeitos de socialização dos pais são estabelecidos de maneira bastante sutil e estão relacionados ao feedback que as próprias crianças oferecem aos mesmos (Fagot e Leinbach, 1989; Fisher-Thompson, 1990).

Estudos têm procurado investigar quais as contribuições, em separado, que pais e mães oferecem para o desenvolvimento do processo de tipificação de gênero de seus filhos (Roopnarine, 1986). Segundo estes estudos, pais e mães são igualmente competentes em participar de atividades e oferecer brinquedos de gênero apropriado para suas crianças. Os resultados obtidos têm indicado que meninos são mais fortemente tipificados do que meninas com relação ao brinquedo $\mathrm{e}$ às atividades físicas em geral, porque seus pais reforçam mais ativamente os jogos de tipificação para seu gênero e punem aqueles tipificados para o gênero oposto (Ignico \& Mead, 1990).

De um modo geral, os pais se preocupam mais que as mães com a tipificação sexual. Com relação a comportamentos de escolha de brinquedos, como são os pais que compram os brinquedos para seus filhos, pesquisadores supõem que suas escolhas estariam, de certa forma, determinando a preferência das crianças (Idle, Wood \& Desmarais, 1993). Estudos têm enfatizado a diferença das expectativas comportamentais dos pais dependendo do sexo de suas criança, bem como indicado que eles reagem diferentemente quando respondendo a solicitações de seus filhos com base na sexo dos mesmos (Weinraub, Clemens, Sockloff, Ethridge, Gracely \& Myers, 1984).

Neste sentido, o principal objetivo deste trabalho foi verificar qual a percepção dos pais sobre sua influência na construção da identidade de gênero de seus filhos.

\section{Método}

\section{Participantes}

Participaram deste estudo 11 pais, 9 mulheres e 2 homens com idades entre 23 e 40 anos, com filhos entre 17 meses e 12 anos. Todos os pais entrevistados têm filhos em idade pré-escolar freqüentando maternais ou creches e residem em Porto Alegre.

\section{Instrumentos e Procedimentos}

As entrevistas seguiram um roteiro semiestruturado. As questões buscaram abarcar os principais aspectos de socialização parental apontados como relevantes para o desenvolvimento da identidade de gênero, segundo a literatura pesquisada. A questões referiram-se às expectativas com relação ao sexo do bebê antes do nascimento $e$ durante a gravidez; quais os sentimentos e reações quando da descoberta do sexo da criança; que expectativas tinham com relação ao bebê, seu comportamento sua personalidade; seus sentimentos e expectativas mudaram ou confirmaram-se quando do nascimento e desde então, especificamente com relação a questões de gênero; imaginam que meninos e meninas são diferentes e devem ser criados de forma 
diferenciada; a que atribuem as diferenças; percebem que suas crianças têm já noção das diferenças entre ser menino ou menina; acreditam que influenciam as escolhas de seus filhos em termos de brinquedos e preferências contribuindo na construção de sua identidade de gênero; que preocupações têm com relação ao futuro de seus filhos.

Os pais que participaram do estudo foram previamente contatados através das pré-escolas e maternais de seus filhos. As entrevistas foram realizadas nas residências dos participantes, em seus locais de trabalho ou nas dependências da universidade, de acordo com a disponibilidade dos mesmos. Todas as entrevistas foram gravadas $\mathrm{e}$ posteriormente transcritas.

\section{Análise dos Dados}

Os resultados obtidos através dos relatos dos pais foram sistematizados, descritos e interpretados segundo a metodologia de análise qualitativa de dados de entrevistas, proposta por Biasoli-Alves e Dias da Silva (1992).

\section{Resultados e Discussão}

A partir da riqueza dos dados obtidos nas entrevistas, buscou-se integrar algumas questões teóricas às respostas emitidas pelos pais entrevistados. Segundo a literatura na área, os pais têm uma importância fundamental no que diz respeito a formação da identidade de gênero das crianças, sendo apontados, ainda, como os maiores responsáveis pelo desenvolvimento dos estereótipos de papel de gênero de seus filhos (Pellett \& Ignico, 1993). N e s t e sentido, o conteúdo das entrevistas aponta para o fato de que, em várias situações rotineiras, os pais demonstram preocupações com relação ao gênero e à formação da identidade sexual de seus filhos.

"Essa coisa de brinquedos, até tem umas bonecas que eu gosto que ele brinque.(...). É pra não ter aquela coisa machista.(...). Já uma coisa que eu não gostaria de vestir de meia de menina, com florzinha, bichinho. Eu não gosto, não sei se este é o meu lado machista. Pra mim boneca não é brinquedo de menina, mas roupinha de florzinha já é

Paidéia, FFCLRP-USP, Rib. Preto, junho/99. muito, não entra na minha cabeça..." (Nara, 23 anos. Mãe de Marcelo, 24 meses.*)

"O meu mais velho adorava bonecas e o meu marido ficava horrorizado." (Leila 38 anos. Mãe de Paulo, 30 meses; Jorge, 8 anos $e$ Fernando, 12 anos.)

"Eu lembro que o André, com 2 anos foi internado com pneumonia lá no Japão, que a gente morava lá, mas o quarto do menino era cor-de-rosa, não o quarto do menino, mas o quarto do hospital era corde-rosa. O pai fez um escândalo: 'ah, meu Deus...', mas eu acho que era mais brincadeira, mas aquilo se a criança ouve, né..." (Ana, 32 anos. Mãe de Pedro, 18 meses e André, 6 anos.)

As crianças manifestam seu conhecimento de papéis de gênero através da categorização de brinquedos e da escolha de atividades feitas segundo este critério (Thompson, 1975; Fagot \& Leinbach, 1989). A preferência por brinquedos marcadamente tipificados para um determinado sexo, tem sido observada como uma das mais precoces manifestações do desenvolvimento do papel de gênero em crianças (O'Brien \& Huston, 1985). O relato dos pais confirma que as crianças realmente preferem brinquedos tipificados para o próprio sexo. Os meninos normalmente preferem brincar com carrinhos, bolas, caminhões, bonecos e blocos; já as meninas, preferem brincar mais de casinha, bonecas, ursinhos e livros de história, segundo a percepção dos pais.

Comportamentos tão precoces com relação à tipificação podem ser explicados pela influência dos pais durante os primeiros anos da criança (Snow, Jacklin \& Maccoby, 1983). Por outro lado, alguns pesquisadores acreditam na possibilidade de uma determinação inata para estas escolhas (Fagot, Leinbach \& Hagan,1986). Outros, sugerem que os eventos sócio-culturais seriam os responsáveis por estas preferências (O'Brien \& Huston, 1985).

Averiguando as crenças dos pais a respeito dos motivos que levam seus filhos a escolherem os

* Os nomes dos participantes foram alterados a fim de preservar seu anonimato. 
brinquedos listados anteriormente, pericebe-se que as opiniões variam. Alguns pais imaginam que estas escoihas acontecem pelo fato das crianças seguirem os exemplos que lhes são passados; outros, atribuem estas escolhas a fatores inatos. Alguns depoimentos apontam para a união entre estes dois fatores.

"Eu creio que é muito pela disponibilidade de mostrar coisas pra ele, porque eles não conhecem e dali eles verem as preferências dele." (Leila 38 anos. Mãe de Paulo, 30 meses; Jorge, 8 anos e Fernando, 12 anos.)

"Eu acho que é de fora, da creche." (João, 40 anos. Companheiro de Maura, 37 anos. Mãe de Cecília, 36 meses e Anelise, 6 anos.)

"Eu acho que é do gosto dela. (...) eu até tento que ela brinque com outras coisas, mas ela não..." (Carla, 27 anos. Mãe de Carolina, 24 meses.)

"Eu acho que é preferência, porque ela tem um monte de bichinhos de pelúcia, mas ela gosta mais de bonecas. É da natureza dela." (Alex, 25 anos. Pai de Marilia, 30 meses.)

"Também tem um pouco dela, só que a irmã influencia muito, né." (Maura, 37 anos. Mãe de Cecília, 36 meses e Anelise, 6 anos.)

Como são os pais que compram os brinquedos para seus filhos, pesquisadores supõem que suas escolhas estariam, de certa forma, determinando a preferência das crianças (Idle, Wood \& Desmarais, 1993). No momento em que os pais foram questionados em relação a quem escolhe ou compra os brinquedos, alguns referem que são os filhos que escolhem os brinquedos. Nos casos em que os pais compram, normalmente escolhem brinquedos tipificados. De alguma maneira preocupam-se em comprar brinquedos tipificados e mostram-se aliviados quando a criança corresponde às suas expectativas.

"A maioria ela ganhou e os outros eu comprei. (...) Eu sempre costumo comprar ursinho". (Silvia, 26 anos. Mãe de Júlia, 24 meses.)
"Ele escolhe, ele pede os brinquedos que ele quer." (Fabiana, 24 anos. Mãe de Augusto,30 meses.)

“Tem umas coisas que ele gosta mais (...) É por escolha dele ou, por exemplo, quando é um caminhão diferente que ele não tenha, aí eu compro pra ele." (Ana, 32 anos. Mãe de Pedro, 18 meses e André, 6 anos.)

"Ela ganha muito. (...) Pro Papai Noel esse foi o primeiro ano que ela pediu e ela pediu um nenê, sempre é nenê que ela pede." (Débora 35 anos. Mãe de Pietro, 17 meses e Bianca, 36 meses.)

Aparentemente há certa pressão social para que os pais selecionem brinquedos capazes de produzir comportamentos apropriados e que as características dos brinquedos podem representar um sexo mais do que outro (Caldera, Huston \& O'Brien 1989). Nas entrevistas, além dos relatos sobre quem costuma comprar os brinquedos, os pais falaram de que modo costumam reagir quando as crianças brincam com brinquedos tipificados para o sexo oposto. Em geral, os pais descrevem que reagem de forma "natural" e tranqüila quanto às escolhas de seus filhos, mas em alguns casos, percebe-se preferência para que as crianças brinquem com brinquedos tipificados para o próprio sexo.

"Bola ela gosta, adora jogar futebol. Mas é super tranqüilo." (Débora 35 anos. Mãe de Pietro, 17 meses e Bianca, 36 meses.)

"... eu acho que se proibir tu está bitolando ele em todos os sentidos, não é por aí." (Fabiana, 24 anos. Mãe de Augusto,30 meses.)

"Ah, não tem muito o que reagir (...) pra mim é normal isso. Eu acho que tem que brincar, passar por todas as fases." (Claudia, 24 anos. Mãe de Gabriela, 36 meses.)

"É tranqüilo, é normal. Eu até acho que ela não é muito arteira, assim de subir, de aprontar, coisa perigosas não." (Camila, 26 anos. Mãe de Marilia, 30 meses.)

Paidéia, FFCLRP-USP, Rib. Preto, junho/99. 
"Eu deixei natural. Disse: olha, quanto brinquedinho, vamos brincar? Olha, tem panelinha de ferro, não quebra, cuidado pra não dar na cabeça da guria.(...) Ele escolheu o trem, ainda bem que foi um brinquedo de guri. (...) Foi ele mesmo que achou o trem ali e ficou todo contente. " (Ana, 32 anos. Mãe de Pedro, 18 meses e André, 6 anos.)

As crianças aprendem a distinguir, através do processo de socialização, o que sua sociedade ou cultura define como masculino e feminino, como por exemplo, os aspectos anatômicos (Bem, 1984). Em relação a percepção das crianças quanto às diferenças anatômicas e sexuais, pode-se perceber que, segundo os pais, elas as identificam desde cedo. Os pais costumam apontar e esclarecer essas diferenças.

"Ele verbalizou pra mim: 'mamãe, eu tenho pinto?'- eu disse: 'tem, tem pinto. E eu tenho o quê?' - Ele disse 'éia'. Então tudo bem. 'Quem mais tem éia?'-perguntei. 'a vovó, a Audrei'. Aí ele viu que tinha uma diferença entre menino e menina". (Fabiana, 24 anos. Mãe de Augusto, 30 meses.)

"Às vezes eu tomo banho com ela, né, ela me olha e diz assim: 'mamãe, eu vô tê teta grande?'-eu digo: 'vai, vai ter teta grande'. Daí ela olha e pergunta: 'eu vô tê cabelo na checheca?'- eu digo: 'vai'. 'Mas eu não quero te teta grande!'." (Claudia, 24 anos. Mãe de Gabriela, 36 meses.)

"Ela toma banho com o pai, aquela coisa de querer pegar o pinto dele. E agora depois que o Pietro nasceu que ela fala: 'ah, papai tem pintinho, o Pietro tem pintinho. A ma mãe e a Bianca tem perereca'." (Débora 35 anos. Mãe de Pietro, 17 meses e Bianca, 36 meses.)

"... um belo dia ela entrou no banheiro e viu o Alex: 'o que é isso?' - aí ele disse: 'ah, é que o papai é homem e a mamãe é mulher, então o papai tem pinto e a mamãe tem peca'
- 'Que nojo!' - achou horrivel!'” (Camila, 26 anos. Mãe de Marília, 30 meses.)

Segundo Maccoby e Jacklin (1974), mesmo na sociedade mais "liberada" de hoje, os pais tratam os filhos de formas diferentes. Nas entrevistas com os pais percebe-se opiniões diversas em relação às diferenças na educação de meninos e meninas. Alguns pais identificam e admitem claramente que há diferenças no modo de criá-los e educá-los.

“(...) as meninas são mais delicadas, (...) no geral elas são mais tranqüilas...Os meninos já não, não param um segundo quietos, são bem mais ativos... Até disseram que na hora de mamar é diferente, os meninos sugam com mais força" (Ana, 32 anos. Mãe de Pedro, 18 meses e André, 6 anos.)

“... não é que seja diferente, mas eu acho que quando a gente cria um homem tem que ter um acompanhamento com um homem, (...) de preferência o pai. (...) eu acho que menina não faz tanta falta. 'Faz', mas acho que pra guri faz mais." (Silvia, 26 anos. Mãe de Júlia, 24 meses.)

"Sei lá, é muito delicadinha e eu vou perder o meu lugar, também. (...) Eu acho que menino é mais capetinha, mais endiabradinho, mais sem-vergonha." (Nara, 23 anos. Mãe de Marcelo, 24 meses.)

Outros pais, referem não haver tais diferenças. Para eles, os cuidados básicos são os mesmos e a maneira como a criança irá se desenvolver depende de como ela entende o que lhe é passado pelos pais e educadores. Entretanto, estes depoimentos mostram-se, muitas vezes, contraditórios.

"Eu acho que não difere muito, dependendo muito da cabeça de cada um, é diferente."(...) "Pôxa, outra filha mulher.(...) eu vou enfrentar uma barra sozinha com cri. ança pequena. Ainda mais mulher, o homem, assim, eu acho que é mais fácil... Ah, porque tu solta um pouco mais, até no fato assim econômico. Financeiramente o homem é 
mais barato pra ti também." (Maura, 37 anos. Mãe de Cecília, 36 meses e Anelise, 6 anos.)

"Eu acho que desde a gestação até os 5, 6 anos o princípio é o mesmo. Os cuidados físicos, psicológicos e morais, tudo isso é igual. Eu acho que diferença entre um homem e uma mulher na realidade não existe... muita gente diz... 'como tu é corajosa por ter tido um filho sozinha! $\mathrm{Na}$ real, elas vivem uma ilusão porque elas acham que o marido ajuda horrores... Porque o homem é muito individualista." (Fabiana, 24 anos. Mãe de Augusto, 30 meses.)

"Eu acho que a gente tem que preparar de uma forma forte, não interessa o sexo. "Eu acho que tu prepara de forma diferente, porque o mundo é mais dos homens, o mundo é machista. Eu acho que a preparação de um guri é mais liberada, mais do que a menina. (Camila, 26 anos. Mãe de Marília, 30 meses.)

Os relatos dos pais demonstram que, mesmo sem perceber, possuem diferentes crenças no que diz respeito aos sexos, ou seja, apontam para a igualdade, mas têm preocupações que indicam um tratamento diferenciado para com seus filhos e filhas. Os pais tendem a preocupar-se mais com as filhas em relação a namorados do que com os filhos. Com relação a drogas, as preocupações são mais acentuadas com os meninos.

"Se tu tens filhos homens, pode vir um bando de amigos dos filhos lá em casa, ficar pra ver guria. Se tiver se agarrando ou não a gente não tá nem aí, mas se tem mulher já não pode, porque daí elas vão se achar no direito de fazer também" (Leila 38 anos. Mãe de Paulo, 30 meses; Jorge, 8 anos $e$ Fernando, 12 anos.)

"Eu acho que ela vai dar incomodação em relação a namorados, ah, vai." (João, 40 anos. Companheiro de Maura, 37 anos. Mãe de Cecilia, 36 meses e Anelise, 6 anos.)

"Só tem uma coisa que eu vou ficar muito triste: eu sou um cara ciumento e, quando pintar um namorado, vai ser mais pro futuro, eu já vou estar bem velhinho! (...) Ela só vai namorar depois do 35!" (Alex, 25 anos. Pai de Marília, 30 meses.)

“Ah, sim, me preocupo com drogas. Eu tô orientando bem eles. (...) Eu tô tentando orientar eles do lado religioso." (Ana, 32 anos. Mãe de Pedro, 18 meses e André, 6 anos.)

“... na adolescência eu tenho medo de drogas, eu tenho medo que ele não me fale as coisas..." (Nara, 23 anos. Mãe de Marcelo, 24 meses.)

De acordo com Papalia e Olds (1998), os papéis sexuais são comportamentos, atitudes e habilidades que uma cultura considera apropriados para o sexo masculino e feminino e espera-se que sejam seguidos. Estes papéis incluem expectativas de personalidade, como por exemplo, que as mulheres sejam condescendentes e carinhosas enquanto que, os homens sejam ativos e competitivos. Os pais entrevistados demonstram que uma série de comportamentos e reações emocionais são considerados "apropriados", para meninos ou meninas, desde o nascimento. Mesmo durante a gravidez da mãe, existem expectativas sobre o comportamento esperado conforme o sexo da criança.

"O Alex (marido) é meio gritão, meio bruto, eu digo: 'se for um guri eles vão me matar, vão me enlouquecer'." (Camila, 26 anos. Mãe de Marilia, 30 meses.)

"Eu acho a menina meiga, bonitinha... eu gosto de mulheres em volta de mim... eu vou ser bem franco: se tiver outro filho, tanto faz se é menina ou menino, mas de preferência eu quero outra menina. Lógico, um filho homem ia ser ótimo, mas ia ser um caos pra mim!"' (Alex, 25 anos. Pai de Marília, 30 meses.)

Paidéia, FFCLRP-USP, Rib. Preto, junho/99. 
"É aquela coisa que as avós dizem, né. Eu ficava: 'ah, isso é lenda'. 'Filho homem é muito mais mimado, muito mais chorão', aquela coisa. O meu é, pelo menos." (Débora 35 anos. Mãe de Pietro, 17 meses e Bianca, 36 meses.)

A maioria dos pais entrevistados tinha expectativas em relação ao sexo do bebê durante a gravidez. Alguns referem que, quando o sexo realmente correspondeu às suas expectativas, ficaram muito felizes. Ao contrário, quando a expectativa e o desejo eram pelo outro sexo, sentiram-se desapontados. Os pais revelaram também como se sentiriam caso o bebê fosse do sexo oposto ao desejado, o que demonstra a importância desta característica para a relação futura com a criança.

“... quando eu vi que era menina eu fiquei assim 'babando'." (Camila, 26 anos. Mãe de Marília, 30 meses.)

"Eu sempre sonhei em ter uma filha mulher.

Foi um grande sonho. Eu sonhava que fosse menina, mas eu falei pra Camila (esposa): 'bá, Camila, eu queria que fosse uma menina, mas eu acho que é guri, infelizmente." (Alex, 25 anos. Pai de Marília, 30 meses.)

"Graças a Deus, ainda bem (...), por que eu sempre me via com um filho, eu nunca me via com uma filha." (Fabiana, 24 anos. Mãe de Augusto, 30 meses.)

"Quando eu soube que era menino, eu chorava, é uma coisa que tu não quer, mas sabe..." (Ana, 32 anos. Mãe de Pedro, 18 meses e André, 6 anos.)

"O meu sentimento era, eu tinha certeza que seria um menino. Quando eu bati a eco, aquilo foi pra mim muito chato, porque eu não esperava." (Maura, 37 anos. Mãe de Cecília, 36 meses e Anelise, 6 anos.)

"Eu pensava que guri eu não ia saber, eu tinha medo de afeminar o guri..." (Silvia, 26 anos. Mãe de Júlia, 24 meses.)
"Pra mim seria mais dificil. Embora eu sendo mulher e pudesse entender muito melhor as fases que a gente passa e tudo o mais,... eu sempre tive muito medo de, embora eu não querendo, passar toda essa rigidez pra minha filha mulher $e$ não aceitar a modernidade." (Leila 38 anos. Mãe de Paulo, 30 meses; Jorge, 8 anos e Fernando, 12 anos.)

Os achados de estudos sobre socialização parental têm indicado que pais e mães têm expectativas comportamentais diferenciadas com relação aos seus filhos e filhas e, utilizam padrões de resposta distintos frente a eles (Weinraub, Clemens, Sockloff, Ethridge, Gracely \& Myers,1984; Eccles, Jacob \& Harold, 1990). Percebe-se que alguns pais notam diferenças nos comportamentos e na educação de seus filhos e filhas já nesta etapa inicial de desenvolvimento. Entretanto, segundo os relatos, em relação a expectativas quanto ao futuro destas crianças, as preocupações são basicamente as mesmas, já que eles desejam que seus filhos sejam felizes, independente de suas escolhas.

Alguns pais falam em profissão e em preocupações financeiras, outros desejam que o filho seja o que eles não foram, como modo de compensar suas frustrações. Em sua maioria, preferem deixar estas escolhas de acordo com a vontade da criança, acreditando que devem apoiá-los e respeitar estas escolhas, como se temessem desejar algo ou não pudessem assumir o que realmente desejam para seus filhos.

"Bom, no futuro dela ela vai ser o que eu não consegui ser ou o que eu não tive a oportunidade de ser. Eu quero que ela seja médica pediatra, psicóloga. (...) Eu brinco, mas eu quero que ela tenha uma profissão, seja auto-suficiente." (Alex, 25 anos. Pai de Marilia, 30 meses.)

"Eu quero que ela faça uma faculdade, por exemplo, eu já não fiz" (Silvia, 26 anos. Mãe de Júlia, 24 meses.)

"Primeiro em relação a personalidade dela, eu acho que tem que ser uma coisa muito 
forte, nitida, transparente, tem que ter uma personalidade pra poder vencer, pra poder sobreviver. Essa é a minha maior preocupaf̧ão agora. Eu acho que ela tem que fazero que ela gosta." (Camila, 26 anos. Mãe de Marília, 30 meses.)

\begin{abstract}
"Pro futuro a gente sempre espera o melhor pros filhos, mas eu não vou interferir no que ela quiser ser (...) não vou querer realizar os meus sonhos através da minha filha porque eu já quis ser tanta coisa! Ah, tomara que não aconteça com ela o que aconteceu comigo! (gravidez indesejada)" (Claudia, 24 anos. Mãe de Gabriela, 36 meses.)
\end{abstract}

"Pro futuro não. Ai, eu acho que ele é tão ligado que eu não sei que futuro ele vai ter. Eu acho que ele vai ficar do meu lado sempre, 'né, meu filho?' (risos) Eu acho que ele vai ter que decidir sobre of futuro dele." (Nara, 23 anos. Mãe de Marcelo, 24 meses.)

\section{Considerações Finais}

Os dados aqui apresentados reforçam a importância da socialização primária na formação da identidade de gênero das crianças. A maneira como os pais influenciam o comportamento de seus filhos demonstrou ser, muitas vezes sutil e indireta, encontrando-se embasada em suas crenças sobre papel de gênero. Estas crenças refletem-se nas expectativas dos pais sobre o comportamento e características de personalidade de seus filhos e influencia suas ações e atitudes frente aos mesmos. Embora, segundo as percepções dos pais, educar e criar um menino ou uma menina não apresente diferenças, contradições em seus depoimentos mostram que as preocupações em relação aos filhos variam conforme o sexo da criança. Sem que possam se dar conta, na maior parte dos casos os pais enfatizam comportamentos que acabam determinando diferenças na aquisição de sua identidade de gênero de seus filhos. As indicações quanto a papéis tipificados de gênero auxiliam as crianças na tarefa de construção de sua identidade de gênero, fundamental para o seu desenvolvimento como um todo. Embora a tipificação de gênero pare- ça exageradamente acentuada na infância ela tente a atenuar-se e flexibilizar-se com o decorrer do desenvolvimento cognitivo. Os pais que participaram deste estudo apontaram, através de seus relatos, para uma relevante preocupação social com respeito ao não incentivo de comportamentos sexistas. Entretanto, dada a importância em termos de saúde e ajustamento, da construção de uma identidade com base na realidade de uma diferença sexual biológica, indicações que possam dar conta da mesma, em especial nos primeiros anos da infância, são necessárias e desejáveis. Em novos estudos, pretende-se abordar, a partir da perspectiva dos educadores, a questão da influência social na aquisição da identidade e do papel de gênero, buscando-se investigar o papel da préescola na aquisição da identidade e tipificação de gênero.

\section{Referências Bibliográficas}

Bandura, A. \& Hudson, A. (1961). Identification as a process of incidental learning. Journal of Abnormal and Social Psychology, 63, (12), 311318.

Bem, S. (1984). Androgyny and gender schema theory: A conceptual and empirical integration. Nebraska Symposium on Motivation, 179-226.

Biasoli-Alves, Z. M. M. \& Dias da Silva, M. H. G. F. (1992). Análise qualitativa de dados de entrevista: uma proposta. Paidéia, 2, 61-69.

Caldera, Y. M., Huston, A. C. \& O'Brien, M. (1989). Social interactions and play patterns of parents and toddlers with feminine, masculine and neutral toys. Child Development, 60,70-76.

Eccles, J. S., Jacobs, J. E. \& Harold, R. D. (1990). Gender role stereotypes, expectancy effects, and parent's socialization of gender differences. Journal of Social Issues, 46, 183-201.

Fagot, B. I. (1978). The influence of sex of child on parental reactions to toddler children. Child Development, 49, 459-465.

Fagot, B. I. \& Leinbach, M. D. (1989). The young child's gender schema: Environmental input, internal organization. Child Development, 60 , 663-672.

Fagot, B. I., Leinbach, M. D. \& Hagan, R. (1986). Paidéia, FFCLRP-USP, Rib. Preto, junho/99. 
Gender labeling and the adoption of sextyped behaviors. Development Psychology, 22, 440443.

Fisher-Thompson, D. (1990). Adult sextyping o children's toys. Sex Roles, 23, 291-303.

Freud, S. (1931). Sexualidade Feminina. Em Obras Completas de Sigmund Freud. Vol. XXI. Rio de Janeiro: Editora Imago, 1974.

Idle, T., Wood, E. \& Desmarais, S. (1993). Gender role socialization in toy play situations: mothers and fathers with their sons and daughters. Sex Roles, 28, 679- 691 .

Ignico, A. A. \& Mead, B. J. (1990). Children's perceptions of the gender-appropriateness of physical activities. Perceptual and Motor Skills, 71, 1275-1281.

Maccoby, E. \& Jacklin, C. (1974). The Psychology of Sex Differences. Stanford, CA: Stanford University Press.

Martin, C. L. \& Havelson, C. F. (1983). Gender constancy: A methodological and theorical analysis. Sex Roles, 9, 775-790.

O'Brien, M. \& Huston, A. C. (1985). Development of sex-typed play behavior in toddlers Developmental Psychology, 21, 866-871.

Papalia, D. E. \& Olds, S. W. (1998). O mundo da criança. São Paulo: Markon Brooks.

Pellet, T. L. \& Ignico, A. A. (1993). Relationship between children's and parent's stereotyping of physical activities. Perceptual and Motor Skills, 77,1283-1289.

Roopnarine, J. L. (1986). Mother's and Father's behaviors toward the toy play of their infant sons and daughters. Sex Roles, 14, 59-68.

Snow, M. E. Jacklin, C. N., \& Maccoby, E. E. (1983). Sex-of-child differences in father-child interaction at one year of age. Child Development, 54, 1493-1503.

Thompson, S. K. (1975). Gender labels and early sexrole development. Child Development, 46, 339347.

Weinraub, M., Clemens, L. P., Sockloff, A., Ethridge, T., Gracely, E. \& Myers, B. (1984). The development of sex role stereotypes in the third year: relationships to gender labeling, gender

Paidéia, FFCLRP-USP, Rib. Preto, junho/99. identity, sex-typed toy preferences, and family characteristics. Child Development, 55, 14931503. 